not, indeed, in the same way as in Mixine, but in a highly instructive and curious manner. The five foremost muscle-segments have their upper extremities attached considerably in front of the nasal opening by a shcrt tendon, which touches its fellow in the middle line; and, extending thence in an outward and backward direction, they pass behind the eyeballs, the first two running in front of the first gillpouch, and the third lying over it. Therefore, in this instance, as surely as the nostril is in front of the cye, so surely the upper extremities of these muscle-segments are shifted forwards out of their morphological place, probably in connection with the great protrusion of the jaws for the physiological purpose of forming a sucker. There is no cscape from granting this shifting, even were it possible to believe that the eycball could be further forward than the nostril; for, while the fifth muscle-segment can be traced in front of the nostril, the sixth occupies the interspace between the skull and first vertebra, so that, if the muscle-segments are taken as a guide, the whole skull, forward to the nostril, belongs to one intersegmental space: a view which is clearly absurd. The succeeding intermuscular septa correspond each with a cartilaginous vertebral arch; and it is interesting to observe that the branchial cartilages are not placed one for each septum, like the fibrous representatives of ribs detectable within the septa; for the second cartilage is opposite the sixth septum, the third opposite the ninth, the fourth opposite the eleventh, the fifth opposite the thirteenth, and the sixth and seventh opposite the fourteenth and fifteenth septa; and this is one reason for doubting that even these superficial branchial cartilages, though attached to the vertebral column, are to be regarded as ribs.

It may be noticed as a wholesome symptom in anatomical speculation, that the new theory which has led to these remarks is founded on arguments drawn altogether from comparison of different species, and not from embryology : a very remarkable circumstance, as coming from one who so lately as last autumn reiterated in this Section his slowness to believe in reasonings founded on adult forms, and even on "later development". The wisest know so little, that humanity must be content to gather information from every possible source, and leave no set of ascertained facts out of view in attempting to arrive at generalisations. If we had before us all the adult anatomy of every species that ever lived on the earth, we should only then have the record completed from which to frame a full system of morphology; and, as matters stand, we must translate embryological phenomena with the aid of the series of alult forms, as well as translate the teachings of the atult series with the aid of embryology.

Falling back on my proposition, that the segments of the vertebrate body are nowhere complete, and that segmentation at one depth may exist to a greater extent than at another, I may mention certain eml:ryological phenomena in the brain which have received too little attention, and which to some extent warrant belief in a larger number of segments in the head than is usually admitted; although I do not see that they are necessarily at variance with that theory of seven segments in every ossified skull which I indicated in 1862 . In the chick, in the middle of the second day of hatching, already is the third cerebial vesicle clivided into a series of five parts, separated by slight constrictions, the first part larger than those which succeed, and the last part narrowing to the spinal cord. The auditory vesicle lies opposite the constriction between the fourth and fifth parts. At the end of the second day and during the third, these divisions assume dimensions which give them a general appearance exceedingly similar in profile to the protovertebrae of the neck. In the following day they exhibit a more complex appearance, and after that the first compartment alone remains distinct as cerebellum, while the divisions between the others disappear in the thickening of the cerebral walls. In their first two tages, Mr. IIuxley, whom I have already referred to so often, has figured these crenations, but he has not, so far as I know, described them.

I may also direct attention to another embryological point, to which I referred last year at Belfast as a probability. I speak now from observation. That which is termed the first cerebral vesicle in the early part of the second day of hatching of the chick, is an undifferentiated region of the brain from which a number of parts emerge successively from behind forwards. As early as the thirty-sixth hour the optic nerves can be traced, separated from the rest of the vesicle by distinct elevations of the floor of the brain, reaching inwards to the constriction between the first and second vesicles : and as early as this date the first trace of bifidity of the brain in front may be discerned-that bifidity which, to my thinking, is only one of several instances of longitudinal fission in the fore part of the head, the trabecula presenting another instance of the same thing, and the cleft between the maxillary lube and the part of the head above it a third; while in the muscular system such longitudinal cleavage or fission is common even in the trunk. In a chick of the third or fourth day, when rendered very transparent, the optic nerves can be seen extending from beneath the front of the optic lobes; while in front of the optic lobes there are placed in series from behind forwards a posterior division of the first vesicle, an anterior division, the cerebral hemispheres, and the olfactory lobes. Thus there is a large supply of material presented in the brain for the study of segmentation: the difficulty to be overcome by future inquiry and careful collation of all available facts is to determine the value of the parts placed one in front of another.

Perhaps I have occupied time too long with matters involving a large amount of technical detail ; but I trust that I may have, in some measure, illustrated that both in aim and in accomplished work anatomy is no mere collection of disconnected facts, no mere handmaid of the physician and surgeon, nor even of physiology. I do not doubt that it is yet destined, as dealing with the most complex sequences of phenomena, to take the highest place among the sciences as a guide to philosophy. One cannot help noticing the increased importance now given to natural history studies as a part of education ; and it is worth while to note that it is most of all in anatomy and physiology that the close connections of matter with mind are brought under review - physiology exhibiting the relations of our own mental being to our bodies, and anatomy revealing a body of organised nature, whose organisation points to a source of beauty and order beyond.

The people of Bristol do well to rally round their medical school. They do well to furnish it with buildings suitable for the prosecution of all the natural history studies which adhere to medical education ; and they do well to join with that school a complete college of literature and science. Let us hope that they will make it worthy of so wealthy and historic a city. But if they will have their medical school the success which in so flourishing a locality public enthusiosm may well make it, and if they will have it aid as well as be aided by a school of general education, let them follow the system latterly adopted in Oxforc and Cambridge, long carried out in the Universities of Scotland, and recognised, though not in all instances sufficiently provided for, in Ireland. Let anatomy, human and comparative, receive its place as an important and fundamental science. Let thorough and adequate provision be made for its being taught as a science; and see that it do not, as in too many medical schools which shall be nameless, degenerate to the etymological and origiral meaning of the word, a mere cutting up of carcasses.

\section{ON TRACHEOTOMY IN CROUP AND DIPHTHERIA.*}

\section{By GEORGE BUCHANAN, M.A., M.D.,} Professor of Clinical Surgery in the University of Glasgow.

Tine prevalence and fatality of diphtheria of late years, as may be seen by a perusal of the Registrar-General's returns, has drawn the attention of the profession to the etiology of that disease, and has recently given rise to a controversy as to the identity or non-identity of croup and diphtheria. Many able papers have appeared in the pages of the BRITISII MEDICAL and other journals on this subject, and to them I refer those interested in the question; but there is one point of resemblance which is of the utmost importance in a practical point of view. Although the two diseases may be as distinct as to cause, course, and sequela, as scarlet fever is from simple tonsillitis, yet both are characterised by the effusion, on the mucous membrane of the air-passages, of a tough false membrane. This membrane may differ in its nature and in situation, at least at the commencement, but the tendency in both cases is to obstruct the breathing and cause suffocation.

This seems so self-evident that I must almost apologise for mentioning it; but $I$ have been so often met with the objection that, because the primary disease causing the effusion is diphtheria and not croup, therefore it is hopeless to interfere, as the operation will not cure the specific disease, that I have considered it not out of place to introduce it. We might as well refuse to open an abscess of the tonsil which was about to choke a patient suffering from scarlatina, because the operation will not cure the fever, as refuse to relieve a patient from instant death from suffocation because the operation is not a cure for diphtheria.

Now, the point I wish to bring out is, that there is a stage both in croup and in diphtheria at which it becomes evident that recovery is hopeless and death from suffocation certain. It is quite true that it is exceedingly difficult to say when that stage has arrived, and mistakes may sometimes occur; but I believe practically it is better to err on the safe side, and acknowledge the inefficacy of treatment, rather than delay till it is too late to resort to the last resource. Tracheotomy pir se, though

* Read before the Surgical Section at the Annual Meeting of the British Medical Association in Edinburgh, August 1875 . 
a difficult, is not a dangerous, operation ; and I, for one, would be inclined to urge its performance before the strength of the little sufferer has been brought to the lowest ebb by the struggles which result from the approaching suffocation.

I wish, however, clearly to guard myself from being supposed to advocate tracheotomy in all circumstances of approaching death from croup or diphtheria. I have elsewhere explained my views on this subject, but I cannot avoid referring to them again.

The diseases in question, but especially diphtheria, when they prove fatal, cause death in one of two ways : either by exhaustion or by suffocation. Hence, we may say there are two varieties, viz., the asthenic and the sthenic. In the great majority of instances, croup is a sthenic inflammation attended with effusion of lymph in the trachea, and proves fatal by suffocation. In some cases, however, the attack is attended with such a depression of the vital powers that the patient sinks apparently from the virulence of the disease. This, however, is a rare case. But in diphtheria there are two well marked types : the sthenic, which closely resembles an attack of sthenic croup, except that the effusion of lymph begins on the fauces and extends through the glottis into the trachea; and the asthenic, which more closely resembles scarlet fever, and in which the effusion covers the whole of the mucous membrane of the fauces, tonsils, and even the pharynx, and in which the false membrane soon becomes foul, putrid, ichorous, and contagious.

In the former of these types, the danger is suffocation; in the latter, it is vital depression, death from asthenia.

Now, with regard to the treatment of these affections at the early stage, I wish here to make no reference; the scope of my remarks is the duty of the medical attendant, when medical treatment has failed, or is clearly failing, to arrest the disease. And I think that it is very important that medical practitioners, especially those commencing practice, should be supported by the opinion of those qualified to advise them in such a delicate matter as this, seeing it is a most painful and disagreeable task to advise parents to submit their children to such a repulsive proceeding.

I believe, then, that I am justified in calling on all those who have seen much of these diseases to unite with me in asserting that, when medical treatment has been fairly tried and when it is proving unavailing, and when death seems imminent from suffocation, not from vital depression or exhaustion, it is the duty of the medical attendant to perform, or advise the performance of, tracheotomy.

I know that here I shall be met with the objection that some cases which seerned hopeless have ultimately recovered; but these isolated examples are very few in number, and are counterbalanced out of all proportion by others in which delay, owing to repugnance to the operation and a hope that symptoms will improve, has deprived the patient of that chance of life which the surgeon can offer.

In pressing this view on my medical brethren, I am aware that $I$ am adding nothing new to what has been frequently advanced by those who have had occasion to operate much in croup and diphtheria, but every year convinces me that it is the duty of those whose experience qualifies them to speak with authority on the matter, to reiterate their convictions, even if it be in nearly identical terms.

Last December, I was called to a case of croup, and when I arrived I found the child, a girl seven years of age, in the last stage of suffocation. The two medical gentlemen in attendance declared that the patient was beyond the reach of surgery. One of them, who had never seen the operation, strongly dissuaded me from making the attempt; the other, who had at one time been one of my clinical students, on hearing my wish to give the child a chance, persuaded the parents to consent. The little patient was livid, and though I did not use chloroform, as I usually do, it did not wince when I made the incision through the skin. The result was that the child is now alive, and in the enjoyment of excellent health.

To one who sees the operation for the first time, the hopelessness as to the attempt is only equalled by the surprise and gratification at the result.

But, while I am so strongly advocating the operation in the circumstances referred to, there is one condition in the suffocative form of those diseases which contraindicates tracheotomy, and which, if discovered, should prevent anyone from performing it. When the suffocation depends not only on obstruction of the trachea, but also on effusion of false membrane or the glutinous fluid which precedes it, into the smaller bronchial tubes, then the case is not one for operation. The difficulty, then, is to discover when the false membrane which causes the obstruction to breathing is limited to the trachea and larynx and when it has invaded the bronchia. Percussion and auscultation ought to assist in the diagnosis, but the restless tossing of the child and the noise of the breathing always make this a difficult proceeding.

There are two signs which appear to me to be valuable guides : one is the amount and loudness of the stridor, which is always great in proportion to the patency of the small tubes and obstruction in the trachea.

But the most valuable test is a view of the naked chest. When the obstruction is in the trachea, while the bronchial tubes are free, the respiratory movements are continued with exaggerated enersy, but the chest will not respond to the muscular efforts. The result is that at each inspiration the flexible parts of the thoracic walls are drawn in with great force, the intercostal spaces are hollowed, and the ensiform cartilage sucked back. But when the small bronchial tubes, and, perhaps, the air-cells, are stopped with the viscid or membranous effusion, the muscular efforts are more feeble and the chest remains puffed out, and the whole aspect is that of a child thirsting for breath, but with the lungs already full and themselves unfit for respiration. In this latter case, I never operate; in the former, with every hope of success.

This is not the place to enter into details with regard to the operation, which vary in many respects in different cases; but one thing may be impressed on the young operator by one who has had considerable experience ; and that is, that tracheotomy is not the simple plunge of a knife into the trachea that many suppose, and that can be easily effected in the bloodless neck of a subject on a dissecting-room table. It requires coolness and patience on the part of the operator. Sometimes the trachea can be exposed by very little dissection; at others, numerous obstacles come in the way, especially in young children. Among these may be mentioned overabundant cellular tissue and fat, turgid veins, isthmus of the thyroid gland, which is very large in infancy, and protrusion into the wound from below of the thymus gland, a frequent cause of surprise and annoyance to those who are not forewarned. In consequence of these possible complications, the operation must be done slowly and systematically, obstacles turned and held aside, bleeding vessels secired ; and the golden rule is that the trachea is never to be opened till its white rings are seen clearly at the bottom of the wound.

The following table contains an account of my operations of tracheotomy in croup and diphtheria, and the respective results.

CASE I. Croup; aged 6. Cured.

II. Croup; aged $3 \frac{1}{2}$. Death in three hours.

III. Croup; aged 3. Death immediately.

IV. Croup; aged $1 / 4$. Death in sixteen hours.

v. Diphtheria ; aged 2. Death immediately.

vi. Diphtheria; aged $21 / 2$. Death in six hours.

vir. Croup; aged $\mathbf{I} 1 / 2$. Death in eight hours.

viII. Croup; aged 3 . Death in twenty-four hours.

Ix. Diphtheria ; aged 4. Cured.

$\mathrm{x}$. Diphtheria; aged $2 \mathrm{1} / 2$. Cured.

XI. Diphtheria; aged $\mathrm{I} 3 / 4$. Death in twenty-four hours.

XII. Croup; aged 5 . Cured.

XII. Diphtheria; aged $21 / 2$. Death in forty hours.

XIV. Croup; aged 5 . Cured.

xv. Diphtheria; aged 5. Death in twenty-eight hours.

xvi. Diphtheria; aged $5 \frac{1}{2}$. Death in five days.

xvir. Diphtheria; aged 6. Cured.

XviII. Diphtheria; aged 3. Death in four days.

xix. Diphtheria; aged $3 \frac{1}{2}$. Death in seven days.

$\mathrm{xx}$. Diphtheria; aged 2. Death ir. five days.

XxI. Diphtheria; aged $2 \frac{1}{2}$. Cured.

xxir. Diphtheria; aged $6:$ Death in two days.

xxiII. Diphtheria; aged 5. Cured.

xxiv. Diphtheria; aged 8. Death in thirteen days.

XXv. Croup ; aged $\mathbf{I} 1 / 2$. Death in six hours.

Xxvi. Croup; aged 5 . Cured.

Xxvir. Diphtheria; aged 5. Death in five day's.

xxviII. Diphtheria; aged 7 . Cured.

xxix. Croup; aged 5 . Death in three days.

xxx. Diphtheria; aged 5. Cured.

xxx. Diphtheria; aged 2. Death in two days.

xxxiI. Croup; aged $21 / 2$. Death in two days.

xxxIII. Diphtheria ; aged 5. Death in six clays.

xxxiv. Croup; aged 9. Cured.

xxxv. Croup; aged 4. Death in three days.

xxxvi. Diphtheria ; aged 8. Death in eight days.

xxxvir. Diphtheria; aged 7. Cured.

xxxviII. Diphtheria; aged 7. Death in three days.

xxxix. Diphtheria; aged 5. Cured.

X1. Diphtheria; aged 5. Death in two days.

XLI. Diphtheria; aged 4. Death in three days.

XLII. Diphtheria; aged 6. Cured.

XLIII. Diphtheria; aged 4 . Death in two days. XLIV. Croup; aged 7. Cured. 
XI.v. Croup; aged 9. Death in four days.

Xlv I. Diphtheria; aged 6. Cured.

Total cases of Tracheotomy, 46. Cured 17 ; Died 29.

Tracheotomy in Croup, 16. Cured 6; Died ro. Diphtheria, 30. Cured I I ; Died I9.

The average result is precisely the same, viz., one child is saved out of every two and two-thirds operated on; and, as the operation was always done when there seemed no hope of recovery otherwise, it may safely be stated that the lives of these seventeen children were saved by tracheotomy.

\section{UNUSUALLY RAPID ACTION OF THE HEART.}

$$
\text { By JOHN CAVAFY, M.D., }
$$

Assistant-Physician to St. George's Hospital.

Dr. FARQUharsoN's interesting paper on this subject, published in the JOURNAL of June I2th, recalls to my mind a very similar case which came under my notice some years ago, and which deserves, I think, to be recorded.

A groom, aged 32, was admitted into St. George's Hospital, under the care of the late Dr. Fuller, on March I5th, I87I. He had suffered from acute rheumatism seven years before, but had presented no cardiac symptoms till his present illness, the history of which was as follows. He had been in the service of a French family, with whom he was shut up in Paris during the siege. In October, his master's horses were killed for food, and he was consequently discharged. Since that time, he had lived very poorly, barely supporting himself by odd jobs of various kinds, and for the last two months had been subjected to great privation. He could obtain no meat, and only small quantities of bread and wine. He grew thin, and became subject, for a fortnight before his admission, to violent palpitation and precordial pain on the least exertion or excitement. The fits of palpitation would often last a whole night. He left Paris on March I 3 th, with only two pounds of bread, and, on reaching Charing Cross, was penniless and destitute. He begged a lodging, and was offered food, but could not eat. The next morning, he swallowed a cup of tea, but this was immediately vomited. Violent pain and palpitation came on, and continued with barely appreciable intervals of rest, till he was admitted into the hospital on the following day.

He was then sweating profusely; there was great dyspnœa, and the heart's action was extremely rapid. The pulsations were counted as follows : at I. 30 (by Dr. Barclay), 228 ; at 2.15 (by myself), 216 ; at 2.20 (by the house-physician), 208 ; a little later (by Dr. Dickinson), 200 ; at 3 (by Dr. Whipham and myself), 176. A few minutes later (by Dr. Jones), the pulse suddlenly became very weak, irregular, and intermittent, and dropped to Ioo-Io8. He was fed with small quantities of egg and brandy mixture every hour. The feeding was continued during the night, which was quiet, with the exception of one comparatively slight attack of pain and palpitation, and, at I I on the following day, I found the pulse irregular, 100 to 108, with occasional intermission, and a harsh systolic murmur was now audible at the apex. Next day, the pulse had fallen to 82 , and he steadily improved. $\mathrm{He}$ gradually became able to take food, the palpitation diminished in force and frequency, and by April rath he was well enough to go to the Convalescent Hospital at Wimbledon. The treatment consisted of egg and brandy mixture, gradually dinininished and replaced by food; bark and ammonia, and latterly citrate of iron and bromide of potassium in effervescing ammonia draught. No digitalis was given.

In this case, there are, it will be seen, many points of similarity to that published by Dr. Farquharson. There was valvular disease, the murmur was inaudible during the very rapid action of the heart, and there was a sudden fall (preceded in my case by a gradual diminution) in the number of pulsations, accompanied by irregular and intermittent action. With regard to the causation of palpitation, it seems probable that, in the great majority of instances, it is due to paresis of the inhibitory fibres of the pneumogastric, and not to stimulation of the accelerator nerves. Palpitation occurs chiefly in anæmic and otherwise weakened patients ; in the case before us, it came on after insufficient food and consequent exhaustion, and it is difficult to suppose that, in cases such as these, there can be increased nervous action of any kind. I am aware that, in exophthalmic goître, the palpitation and increased action of the heart are considered by some to be owing to stimulation or irritation of the accelerator nerves. But even here the majority of symptoms-dilatation of arteries, flushing, heat, sweating, etc.-point to paralysis of the sympathetic, or at least of the vaso-motor nerves. Friedreich has suggested that the increased action of the heart is secondary to vaso-motor paralysis, the coronary arteries being thus dilated, and the heart in consequence receiving an increased blood- supply. It should, however, be remembered that dilatation of arteries means diminution of blood-pressure, and that this always increases the frequency of the heart's contractions. A high blood-pressure, on the contrary, stimulates the centre of origin of the pneumngastric, and thus diminishes the frequency of the pulse.

\section{THE LATE DISCUSSION ON PUERPERAL FEVER, AND ON ITS TREATMENT BY INTRAUTERINE INJECTIONS.}

\section{By EDWARD JOHN TILT, M.D.}

WHEN, in opening the discussion, Mr. Spencer Wells stated that he came to learn and not to teach, those who hold him in high esteem thought this was only the usual artifice of the orator, seeking to moderate expectations so as to ensure the success of a final effort; and great was. our surprise, when his turn came to close the debate, to find that he had trotted us out to show our paces, without having any definite object in view. Henceforth this discussion will be memorable among others; for, although the business of the Society was suspended for four consecutive meetings, and although the discussion was well carried on by many men well prepared by length and quality of observation, and who did their best to put their thoughts in small compass, no one gave them their proper place and weight in a general résumé of the debate; for this was left undone by Mr. Spencer Wells, by the President of the Society, and by the principal organs of the medical press.

I have no intention to do the work that should have been done by others; ; but, before responding to an appeal made to me by a correspondent in the issue of the British Association Fournal of July I 7 th, that I should more fully state the best means to evacuate the foetid contents of the womb, I propose to make a few remarks on puerperal fever. I am glad of the opportunity to rectify the apparent one-sided: ness of the remarks I made at the Obstetrical Society; for it is obviously advisable, when a speaker has to treat a vast subject in fifteen minutes, that he should devote the time to the elucidation of some undervalued point of practice rather than to the delivery of a mere syllabus of his views of the subject.

I am not aware that I am indebted to the discussion for any new views on puerperal fever; but it has deepened the conviction I already entertained, and I hold :- I. That, during the puerperality, the blood is in such a state " of trembling equilibrium", to use Dr. Richardson's happy expression, that the unknown poison of puerperal fever may be developed within the blood by cold, or mental emotion, or zymotic influence, while the lochia remain perfectly normal. I say may, for sometimes even the poison of scarlet fever follows its usual course in a puerperal patient without causing puerperal fever, and without in the least interfering with the healthy tenor of the puerperal processes. 2. That, the womb and lochia being in a healthy condition, cold, mental emotion, or zymotic influence may render the lochia putrid, and thereby develope a poison which, soaking into the surface of the womb and its sinuses, is taken up by the uterine lymphatics, which pass it into the blood, so as to cause puerperal fever. 3. That the seat of placental attachment, a bruised portion of the womb, or any rent in its tissue, may inflame unhealthily, and thus produce pyrogenic fluids, which may be taken up by the lymphatics and cause puerperal fever, as already mentioned. 4. That fragments of placenta, of the membranes, and blood-clots, if retained in the womb, decompose, and produce septic fluids which may cause puerperal septicæmia. 5. That, as with other patients, so with puerperal women, when attacked by zymotic influence, the whole of their secretions may be vitiated, so that scarlatina, for instance, may poison the lochia, if it find them healthy, or intensify the virulence of the poison if it find them already made putrid by any of the causes previously enumerated. 6. That, just as other poisons often pass through the lymphatics into the blood without inflaming them, so the poison of puerperal fever may pass through the uterine lymphatics into the blood and into the peritoneum without inflaming the lymphatics sufficiently to fill them with pus; extensive purulent lymphangitis being rather the exception than the rule, unless certain epidemic influences prevail.

For all that relates in the previous propositions, to the mode in which the lymphatics convey from the womb the poison which, on coming in contact with puerperal blood, lights up puerperal fever, as well as for the explanation of the very early advent of puerperal peritonitis and the subsequent occurrence of puerperal cellulitis, pelvic abscess, and ovaritis, I refer the reader to my paper on Lymphangitis in Pelvic Pathology, in the sixteenth volume of the Transactions of the Obstetrical Society of London. Those who take interest in this mo- 